\title{
A Study on Grading Early Warning Model of Distribution Network Investment Deviation
}

\author{
Cai Hui ${ }^{1}$, Liu Dunnan ${ }^{2}$, Zhou Long ${ }^{1}$, Tang Tianqi ${ }^{2, *}$ \\ ${ }^{1}$ Guangdong Power Grid Corporation, Guangzhou, Guangdong province China \\ ${ }^{2}$ North China Electric Power University, Beijing, China
}

\begin{abstract}
The grading early warning model of distribution network investment deviation can invest in distribution network construction project and provide scientific and economic management model. In this paper, factors that caused distribution network construction investment deviation has been identified effectively, the distribution network construction investment deviation early warning index system was built through the selected technical-economic indicators; furthermore, a comprehensive analysis of investment deviation by using analytic hierarchy process was carried out, and then, started from fuzzy evaluation and grey evaluation method, a investment deviation early grading model that combined with fuzzy and grey was established. In this paper, a concrete example was given to demonstrate the smart grid investment deviation grading early warning model is practical.
\end{abstract}

\section{Introduction}

Further deepen the reform of investment and construction system of electric power engineering, has made the investment and construction pattern of electric projects gradually integrate with international standards, and the process management of investment and construction projects has drawn more and more attention of electric investment and construction industry. Scholars at home and abroad have studied distribution network project. Literature 1 studied economic operation of distribution network and examined its investment efficiency; Literature 2 focused on investment decisions and investment optimization of distribution network; Literature 3 identified and evaluated the risk in the course of the construction of distribution network. Thus it can be seen that the study on the analysis of distribution network investment deviation is less, and there is lack of the study on universal method targeted to correct and optimize distribution network investment deviation.

In this case, this paper based on related research results of scholars at home and abroad, carefully identified the cause of distribution network construction project investment deviation, started from the main factors and extracted the index set of grading early warning; After selecting indicators, through the analytic hierarchy process to analyze these factors and determine the weight of each index in each level factors; Then synthesized fuzzy, grey evaluation method, using grey clustering theory to get grey statistics, and then constructed the fuzzy membership matrix; Finally using fuzzy algorithm evaluation to judge project results of investment deviation grading early warning.

\section{The framework of investment deviation early warning index system}

\subsection{Analysis of the reason of investment deviation}

Investment deviation is the differences between the actual investment and planned investment during the investment control. Construction project investment deviation caused by many reasons, these factors influence the whole construction process of the project. The objective reason includes social factor, natural factor and economic policy; the design reason includes problems like structure change, design standard change, design error or defect during the design process; the owner's reason includes inappropriate coordination and improper investment planning during the whole implementation process of the project; the construction reason includes improper construction schedule, unreasonable construction and quality accidents. To reduce investment deviation and control investment effectively, people must recognize the factors that caused investment deviation and make quantitative analysis, thus proposing solutions to the main effect factors.

\subsection{The content of index system}

Investment deviation index system as shown in Chart 1 below, the first layer is the purpose layer, the second layer is the factor layer and the third layer is the index layer.

Table 1 The cause model of investment deviation index system

\begin{tabular}{|c|c|c|}
\hline $\begin{array}{l}\text { The } \\
\text { purpose } \\
\text { layer }\end{array}$ & $\begin{array}{l}\text { The factor } \\
\text { layer }\end{array}$ & The index layer \\
\hline \multirow{12}{*}{$\begin{array}{l}\text { Investment } \\
\text { deviation } \\
\text { A }\end{array}$} & \multirow{3}{*}{$\begin{array}{l}\text { The objective } \\
\text { reason } \mathrm{B} 1\end{array}$} & Social factor C11 \\
\hline & & Natural factor C12 \\
\hline & & Economic factor C13 \\
\hline & \multirow{3}{*}{$\begin{array}{l}\text { The owner's } \\
\text { reason B2 }\end{array}$} & $\begin{array}{l}\text { Inappropriate coordination } \\
\mathrm{C} 21\end{array}$ \\
\hline & & $\begin{array}{l}\text { Improper investment } \\
\text { planning C22 }\end{array}$ \\
\hline & & Other reasons C23 \\
\hline & \multirow{3}{*}{$\begin{array}{l}\text { The design } \\
\text { reason B3 }\end{array}$} & Structure change C31 \\
\hline & & Design standard change C32 \\
\hline & & Design error or defect C33 \\
\hline & \multirow{3}{*}{$\begin{array}{l}\text { The } \\
\text { construction } \\
\text { reason B4 }\end{array}$} & $\begin{array}{l}\text { Improper construction } \\
\text { schedule C41 }\end{array}$ \\
\hline & & $\begin{array}{l}\text { Unreasonable construction } \\
\text { C42 }\end{array}$ \\
\hline & & Quality accidents C43 \\
\hline
\end{tabular}




\section{The construction of investment deviation grading early warning model}

3.1 Using the analytic hierarchy process (ahp) to determine the weight of investment deviation evaluation index

(1) Building judgment matrix

Judgment matrix is using an element of top level as the evaluation target, by making pairwise comparison of the relative importance of each index in this level to determine the matrix elements, and establishing judgment matrix eventually:

$$
A=\left(\begin{array}{cccc}
a_{11} & a_{12} & \cdots & a_{1 n} \\
a_{21} & a_{22} & \cdots & a_{2 n} \\
\vdots & \vdots & \ddots & \vdots \\
a_{n 1} & a_{n 2} & \cdots & a_{n 3}
\end{array}\right)
$$

Above formula: $a_{i j}$ represent the importance that $A_{i} A_{j}$ in relative terms of evaluation target, the value of $a_{i j}$ is determined by 1-9 scaling method with the comprehensive expert group opinion. 1-9 scaling method and its meaning as shown in table 2.

Table 2 the scaling method to judge matrix elements

\begin{tabular}{|c|c|}
\hline $\begin{array}{c}\text { The value } \\
\text { of } a_{i j}\end{array}$ & Description \\
\hline 1 & $A_{i}$ and $A_{j}$ are equally important \\
\hline 3 & $\begin{array}{c}A_{i} \text { is slightly more important } \\
A_{j}\end{array}$ \\
\hline 5 & $A_{i}$ is a little more important \\
than $A_{j}$ \\
\hline 7 & $A_{i}$ is more important than $A_{j}$ \\
\hline 9 & $A_{i}$ is severe more important \\
than $A_{j}$ \\
\hline $2,4,6,8$ & $\begin{array}{c}\text { The scale value between the above } \\
\text { two judgments }\end{array}$ \\
\hline Reciprocal & $a_{i j}=1 / a_{j i}, a_{i i}=1$ \\
\hline
\end{tabular}

(2) Solving the normalized relative important degree vector $W_{0}=\left(W_{i}^{0}\right)$ of each element that related to some element in the upper layer. Using the square root method, that is:

$$
\overline{W_{i}}=\left[\prod_{j=1}^{n} a_{i j}\right]^{\frac{1}{n}}
$$

$$
W_{i}=\frac{\overline{W_{i}}}{\sum_{j=1}^{n} \overline{W_{j}}}
$$

(3) Calculating the maximum eigenvalue of judgment matrix $\lambda_{\max }$ and the C.I. (Consistency Index), making a one-time test.

$$
\begin{aligned}
& \lambda_{\max }=\frac{1}{n} \sum_{i=1}^{n} \frac{(A W)_{i}}{W_{i}}=\frac{1}{n} \sum_{i=1}^{n} \frac{\sum_{j=1}^{n} a_{i j} W_{j}}{W_{i}} \\
& \text { C.I. }=\frac{\lambda_{\max }-n}{n-1}
\end{aligned}
$$

Getting the total importance of all indexes based on the calculation of weights and sorts structure of judgment matrix.

\subsection{The fuzzy grey comprehensive evaluation of investment deviation grading early warning model}

(1) Determine the sample matrix of evaluation vector

Assuming there are $r$ experts evaluating the index layer based on evaluation rules and having the evaluation vector $\left(d_{i j 1}, d_{i j 2}, \ldots, d_{i j r}\right)$ of index j of factor i. Then all the comprehensive evaluation vectors of index $j$ of factor i can be written as

$$
d_{i j}=\frac{\sum_{k=1}^{r} l d_{i j k}}{r}
$$

(2) Determine the evaluation sets and establish the grey type of evaluation

According to the "Overall contingency plan of National Public Emergencies "issued by the State apartment in 2006, the public emergencies need to be set alert level based on the predicting analysis results, the alert level of this model warning is divided into 4 levels, defining early warning grading evaluation sets as A \{blue (B), yellow $(\mathrm{Y})$, orange $(\mathrm{O})$, red $(\mathrm{R})\}$, on behalf of the general, the greater, the significant and the special serious respectively, accordingly, 0 <early warning coefficient $<0.2$ for the general, $0.2 \leqslant$ early warning coefficient $<0.5$ for the greater, $0.5 \leqslant$ early warning coefficient $<0.8$ for the significant, $0.8 \leqslant$ early warning coefficient $<1$ for the special serious.

To determine the grey type of evaluation is to determine the number of levels, the grey number and the whitenization weight functions of the grey type of evaluation. Grey type is determined by evaluation levels and qualitative analysis. Thus according to the evaluation sets, the following four whitenization weight functions can be established.

1) The whitenization weight function that belongs to the lower limit of general measure is as follows: 


$$
f_{1}\left(d_{i j}\right)=\left\{\begin{array}{l}
1, d_{i j} \in(0,0.2) \\
\frac{0.5-d_{i j}}{0.5-0.2}, d_{i j} \in[0.2,0.5] \\
0, d_{i j} \notin(0,0.5)
\end{array}\right.
$$

2) The whitenization weight function that belongs to the greater limit of general measure is as follows:

$$
f_{2}\left(d_{i j}\right)=\left\{\begin{array}{l}
\frac{d_{i j}}{0.2}, d_{i j} \in(0,0.2) \\
1, d_{i j} \in[0.2,0.5] \\
\frac{0.8-d_{i j}}{0.8-0.5}, d_{i j} \in(0.5,0.8) \\
0, d_{i j} \notin(0,0.8)
\end{array}\right.
$$

3) The whitenization weight function that belongs to the significant limit of general measure is as follows:

$$
f_{3}\left(d_{i j}\right)=\left\{\begin{array}{l}
\frac{d_{i j}-0.2}{0.5-0.2}, d_{i j} \in(0.2,0.5) \\
1, d_{i j} \in[0.5,0.8] \\
\frac{1-d_{i j}}{1-0.8}, d_{i j} \in(0.8,1) \\
0, d_{i j} \notin(0.2,1)
\end{array}\right.
$$

4) The whitenization weight function that belongs to the special serious limit of general measure is as follows:

$$
f_{4}\left(d_{i j}\right)=\left\{\begin{array}{l}
\frac{d_{i j}-0.5}{0.8-0.5}, d_{i j} \in(0.5,0.8) \\
1, d_{i j} \in[0.8,1] \\
0, d_{i j} \notin(0.5,1)
\end{array}\right.
$$

(3) Calculating the grey statistics and establishing fuzzy membership matrix

Calculating the grey statistics of $d_{i j}$ that belongs to $f_{1}\left(d_{i j}\right), f_{2}\left(d_{i j}\right), f_{3}\left(d_{i j}\right), f_{4}\left(d_{i j}\right)_{\text {respectively, }}$ and getting the vector $\left(r_{i j 1}, r_{i j 2}, r_{i j 3}, r_{i j 4}\right)$ through normalization processing, this vector is the fuzzy membership that factor $\mathrm{i}$ index $\mathrm{j}$ belong to(the general, the greater, the significant and special serious), and establishing fuzzy membership matrix $R^{i}$ of factors i.

(4) Fuzzy comprehensive evaluation

Comprehensive value $B_{i}$ of the factors $I$ is:

$$
B_{i}=\left[b_{i 1}, b_{i 2}, b_{i 3}, b_{i 4}\right] \quad b_{i 1}=\sum_{k=1}^{i} a_{k 1} r_{k j 1}
$$

$$
\begin{aligned}
& b_{i 2}=\sum_{k=1}^{i} a_{k 2} r_{k j 2} \quad b_{i 3}=\sum_{k=1}^{i} a_{k 3} r_{k j 3} \\
& b_{i 4}=\sum_{k=1}^{i} a_{k 4} r_{k j 4}
\end{aligned}
$$

According to the subjection vectors of each index in this level of subsystem, we can constitute a total evaluation function matrix: $R=\left[B_{1}, B_{2}, \ldots, B_{i}\right]^{T}$, calculating the fuzzy matrix of $\mathrm{R}$ again, get fuzzy evaluation matrix $\mathrm{B}$ of the system: according to the maximum membership degree principle: when $B_{1}=\max \left\{B_{1}, B_{2}, B_{3}, B_{4}\right\}$, the alert level is the general; when $B_{2}=\max \left\{B_{1}, B_{2}, B_{3}, B_{4}\right\}$, the alert level is the greater; when $B_{3}=\max \left\{B_{1}, B_{2}, B_{3}, B_{4}\right\}$, the alert level is the significant; when $B_{4}=\max \left\{B_{1}, B_{2}, B_{3}, B_{4}\right\}$, the alert level is the special serious.

\section{Concrete example}

This example was from a distribution network

\begin{tabular}{|c|c|c|c|c|c|}
\hline \multirow{2}{*}{$\begin{array}{l}\text { The } \\
\text { weight } \\
\text { in layer } \\
\text { B }\end{array}$} & B1 & B2 & B3 & B4 & \multirow{2}{*}{$\begin{array}{l}\text { The } \\
\text { weight } \\
\text { in layer } \\
\text { C }\end{array}$} \\
\hline & 0.054 & $38^{0.5}$ & $31^{0.2}$ & $77^{0.1}$ & \\
\hline C11 & 0.124 & & & & 0.007 \\
\hline C12 & 0.238 & & & & 0.013 \\
\hline C13 & 0.638 & & & & 0.035 \\
\hline C21 & & 0.158 & & & 0.085 \\
\hline C22 & & 0.326 & & & 0.175 \\
\hline C23 & & 0.516 & & & 0.278 \\
\hline C31 & & & 0.189 & & 0.044 \\
\hline C32 & & & 0.761 & & 0.176 \\
\hline C33 & & & 0.050 & & 0.012 \\
\hline C41 & & & & 0.173 & 0.031 \\
\hline C42 & & & & 0.489 & 0.087 \\
\hline C43 & & & & 0.338 & 0.060 \\
\hline
\end{tabular}
construction project in some province, the investment deviation grading early warning model was set up, and the quantitative results of the study was collected.

(1) Through hiring experienced experts to score for the indexes weight sets $a_{i j}$ in formula(1), we can get comprehensive index weighting table as follows:

Table 3 The weight value of indexes in layer B and C

Putting the weight in layer $C$ into vectors:

$A=[0.007,0.013,0.035,0.085,0.175,0.278,0.044,0.176$, $0.012,0.031,0.087,0.060]$

(2) Determine the grey evaluation matrix of B layer

According to the rules of evaluation, employing a number of power experts to give the index system a score in (0-1), with the formula 


$$
d_{i j}=\frac{\sum_{k=1}^{r} l d_{i j k}}{r} \text { : }
$$

Table 4 The evaluation value of indexes

\begin{tabular}{|c|c|c|c|c|c|}
\hline \multicolumn{2}{|c|}{} & B1 & B2 & B3 & B4 \\
\hline \multirow{3}{*}{$d_{i j}$} & $\mathrm{j}=1$ & 0.22 & 0.19 & 0.71 & 0.88 \\
\cline { 2 - 6 } & $\mathrm{j}=2$ & 0.57 & 0.38 & 0.21 & 0.25 \\
\cline { 2 - 6 } & $\mathrm{j}=3$ & 0.35 & 0.13 & 0.45 & 0.51 \\
\hline
\end{tabular}

According to the whitenization weight functions (6), (7), (8), (9), we can get the evaluation coefficient of each index that evaluated grey type, having normalization processing to each evaluation coefficient, then we can get the grey evaluation weight vector $r_{i j}$ for each evaluation index of each grey, and establishing a fuzzy membership degree matrix $R$ :

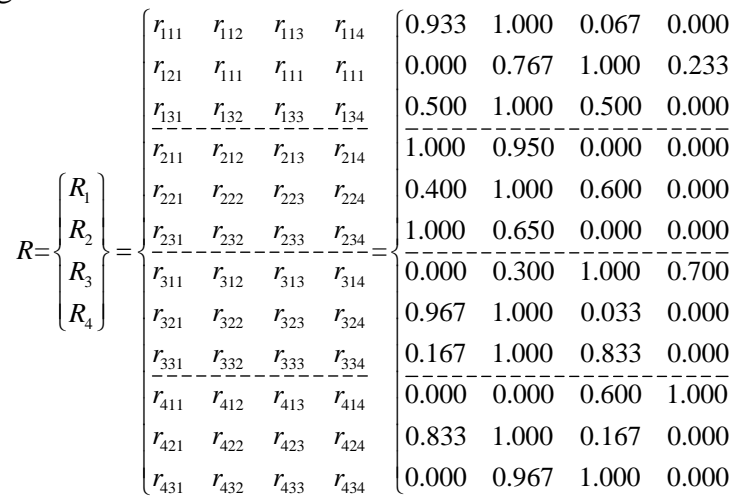

(3) Fuzzy comprehensive evaluation

Calculating fuzzy evaluation matrix $B$ : $B=A \times R=[0.7017,0.8346,0.2889,0.0648]$

According to the principle of maximum degree of membership, the smart distribution grid investment deviation warning level is greater. After the comparison of the weights of different factors that caused investment deviation in construction project, the most significant one is the weight of the design reason, the owner' reason is the second. In the design reasons, the most important one is the design error and defect, second one is the design standard change, and the structural change is less obvious. In the owner's reasons, the most important one is the improper investment planning, second one is the inappropriate cooperation, and the other reasons are less obvious.

\section{Conclusions}

In this paper, factors that caused distribution network construction investment deviation has been identified effectively, the distribution network construction investment deviation early warning index system was built through the selected technical-economic indicators; furthermore, started from fuzzy evaluation and grey evaluation method, a investment deviation early grading model that combined with fuzzy and grey was established, making full use of the fuzzy and grey of the information that expert judged. Finally in this paper, a concrete example was given to demonstrate the model established before is practical.

\section{References}

[1] Li Juan, Li Xiaohui, Liu Shuyong. Investment Benefit Evaluation for Distribution Network Based on TOPSIS and Grey Correlation Degree [J]. East China Electric Power, 2012,01:13-17.

[2] Fang Lue, Cheng Haozhong, Liu Lu. Evaluation of 10 kV Distribution Network Investment Allocation Based on Multi-Index System [J]. East China Electric Power, 2014,06:1092-1097.

[3] Tang Mingyang. The Analysis and Evaluation of Investment risk in Distribution Network Construction Project [D].North China Electric Power University (Hebei), 2009. 